\title{
Usability of Public Transport for Differently abled People in Sri Lanka
}

\author{
W.K. Mampearachchi and S. Suman
}

\begin{abstract}
As a developing country, public transport is a vital part of the National transport system. In Sri Lanka, Buses, Trains, Vans, and Three wheelers are widely used as public transport modes. Even though Sri Lanka has almost adequate numbers of fleet in each public transport modes, they do not have sufficient facilities for differently abled people.

It has been found that number of differently abled people has increased significantly due to the civil war which was ended in 2009. The differently abled people are the people who have only certain limitation on their activities. It was found that majority of them are not employed and depend on their families for survival. So the public transport system should be accessible, usable and safe for differently abled people to join them for the economic development of Sri Lanka.
\end{abstract}

There should be well developed specifications such as TRL Overseas Road Note 21 and DPTAC manual for public transport modes to accommodate differently abled people. In Sri Lanka, the Gazette of Democratic Socialist Republic of Sri Lanka No 1,467/15 dated on 17/10/2006 [2] is the only one available, but, it does not have much detailed specifications. Therefore, the need of a new specification has been emphasized in this study.

The problems in public transport modes in serving differently abled people of Sri Lanka were gathered through a questionnaire survey by mail. Response of three types of disabilities; visually, hearing and physical impaired were analyzed in the study to understand the accessibility issue of differently abled people. Detailed survey of public transport facilities was conducted to identify the suitability of available transport modes for differently abled people. Survey on the existing transport modes showed that most of the vehicles that are used in public transport do not have adequate facilities for the differently abled people.

Keywords: Public Transport, Differently Abled People

\section{Introduction}

The physical environment which is not favourable for differently abled people makes a barrier to activities of them. To have a barrier free public transport system, it is required to improve the road environment and public transport system to serve differently abled people.

According to the thirteenth census of population and housing statistic data [8] which was conducted on $17^{\text {th }}$ of July 2001, the types of disabilities which have highest percentages are mobility impairment with $24.9 \%$ and vision impairment with $19 \%$ among all types of disabilities. But the ADB report [3] states that now these percentages will be much higher than those given here due to civil war.

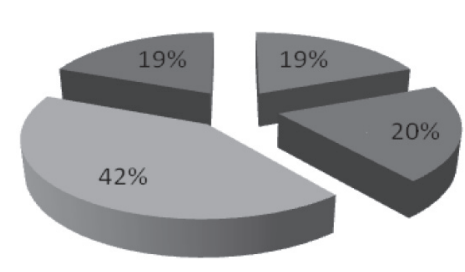

Disability in Seeing

Disability in Hearing/Speakir

- Physical disabilities

- Mental disabilities

Figure 1 - Distribution of Impairments of Differently Abled People in Sri Lanka




Figure 1, shows that, Percentages of disabilities in physical, hearing, seeing and mental are $42 \%, 20 \%, 19 \%$ and $19 \%$ respectively in 2001 .

The two key factors to be considered in increasing accessibility of differently abled people are disable friendly improvement in road environment and transportation modes. This study is concentrated on usability of available transportation modes (vehicles) for differently abled people. It was found that Three wheelers, Buses, Trains, and Cabs are the available public transport modes in Sri Lanka. Three wheelers are small scale vehicles which are unable to be modified to accommodate differently abled people. This study is mainly focused on public transport mode such as Buses, Trains, information related to journey and terminals.

TRL ORN 21[9] and DPTAC manual [4] were reviewed in the study. It was found that the standard specified in both specifications does not have significant differences. The currently available Sri Lankan standard for public transport has not been specifically considered the need of differently abled people. This emerges a new set of specifications to be developed based on Sri Lankan situation.

\section{Literature Survey}

The study team has studied international standard for disabled friendly public transport modes. The literature survey was focused on the existing specifications which are currently used by other countries effectively [2] [5] [6] and [7].

Various studies have been conducted in the past and the specifications have been developed for the most problematic elements in Buses, Vans, and Trains. TRL ORN-21 is developed such that which can be applicable to developing countries. The specifications which are given in TRL ORN 21 are developed mainly based on DPTAC manual.

TRL Overseas Road Note 21 describes specifications for Buses, Vans, and Trains under the following categories.

* Boarding of wheelchair users

* Wheelchair lift size

* Bus entrance

* Handrails

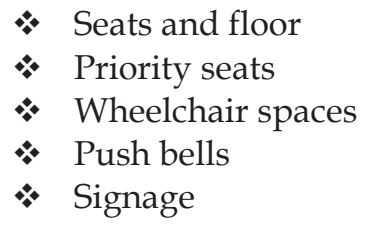

Assessment of accessibility standards for disabled people in land based public transport vehicles says that a survey conducted by DPTAC shows $61 \%$ of differently abled people were likely to plan their journey in advance with the provided travelling information in England and Wales. This concludes that the information about journey is important for the differently abled people.

The specifications for the terminals are given in the following standards.

\section{* TRL Overseas Road Note 21 \\ * BS8300 [1]}

The specifications for terminals given in TRL Overseas Road Note 21 were developed based on BS8300 and hence it was selected as the basis for the development of specifications for the terminals.

Clause 13.1 of the code of practice BS8300 describes about various elements related to the terminals. The following sections were selected based on the Sri Lankan conditions.

Location of terminal
Entrance
* Ticcessible ramp counter
* Toilet and bathroom
* Access to the transport modes

\section{Methodology}

This research was conducted to develop specifications for public transport modes in Sri Lanka to make them as disable friendly vehicles. So that it is necessary to understand the actual problems faced by differently abled people with public transport modes and state of the available public transport modes in Sri Lanka.

The difficulties faced by differently abled people with public transport modes were gathered through a questionnaire survey and the short comings of public transport modes 
were identified by conducting a survey on public transport vehicles.

\subsection{Questionnaire Survey}

A draft questionnaire survey form was prepared in three languages to gather following details;

* Personal details of differently abled people such as their education level, type of disability, etc.

* Information about their travelling patterns.

* Difficulties faced with transport modes.

* Personal preferences.

A pilot survey was conducted at Ragama Rehabilitation Hospital. Based on the result from the pilot survey, the questionnaire survey form was modified.

Following three methods were tested for the questionnaire survey;

* Conducting survey by meeting differently abled people in person.

* Conducting survey by telephone (except people with deaf).

- Conducting survey by mail.

Then, based on the pilot survey it was found that the conducting survey by mail is more effective than other methods considering the cost and other socio-economic background of the participants for the pilot survey. The contact details of differently abled people were obtained with the help of two organisations; Disabled Organisation Joint Front (DOJF) and Rehab Lanka. A sample with 100 differently abled people was selected randomly as given in Table - 1. However, the response rates of the people were around $50 \%$. It was experienced during the survey that people expect some monitory donations as an aid. If there was an incentive package for successfully completed survey forms, the response rate could be increased.

It was revealed from the survey that most of the time; differently abled people are staying with family members and depend on family for living and hence they do not know the difficulties which will be faced by them during travelling. The differently abled people who are working most of the time use their own vehicle for travelling so that they are exposed to public transport very rarely.

Activity diary for three consecutive days was obtained to understand the trips made by differently abled people in Sri Lanka. It was found that all the unemployed participants spend significant time for watching TV and listening radio.

Table 1 - Survey Sample

\begin{tabular}{|l|c|c|c|}
\hline \multirow{2}{*}{ Disability } & \multirow{2}{*}{ Amount } & \multicolumn{2}{|c|}{ Gender } \\
\cline { 3 - 4 } & Male & Female \\
\hline $\begin{array}{l}\text { Physically } \\
\text { impaired }\end{array}$ & 60 & 40 & 20 \\
\hline $\begin{array}{l}\text { Hearing } \\
\text { impaired }\end{array}$ & 15 & 7 & 8 \\
\hline $\begin{array}{l}\text { Seeing } \\
\text { impaired }\end{array}$ & 25 & 15 & 10 \\
\hline
\end{tabular}

\subsection{Survey on Existing Transport Modes}

Survey on existing public transport modes was conducted to understand the problem faced by differently abled people in using the transport modes. Based on the literature survey, the following list was prepared to gather status of public transport modes in Sri Lanka.

* Dimensions of various elements

- Width of entrance

- Step height

- Height of floor

- Spacing between seats

* Colour contrast

* Availability of wheelchair boarding devices

* Condition of seats

* Availability of priority seats and wheelchair space

* Availability of push bells

* Condition of handrails

* Signage on the vehicles

- Size of letters

- Location of sign board

\section{Analysis and Results}

Analysis of questionnaire survey and condition survey of existing transport modes are presented. 
4.1. Questionnaire Survey Analysis

The general findings of the question survey are summarized below:

i. The response to the questionnaire survey was only $50 \%$ which shows the people are not interested to participate in mail surveys.

ii. The survey team had contacted the participant before sending the questioner and two reminders were given to increase the response rate for the survey.

iii. Majority of the participants do not have an occupation and only $10 \%$ of the responded had been employed as in Figure -2 below.

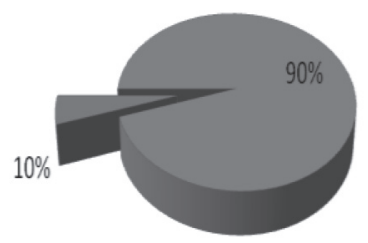

- Unemployer (Home based activities)

Employers

Figure 2 - Distribution of Sample Based on Job Opportunity

iv. Majority of them do not own a vehicle.

v. It was found that employees make only the work related trips and trips to school if they are students.

vi. They visit once or twice a month to hospital for their medical care.

vii. They do not make trip to certain essential personal and social activities such as personal care and religious activities etc,

viii. Majority of them make trips by three wheelers.

The main finding from the questionnaire survey regarding the problems faced with public transport modes by differently abled people are listed below.

1) When travelling by bus
a) Uneven steps
b) Steps height is too high
c) Difficult to get in and get down
d) Congestions in buses and uncomfortable travelling.
e) Difficult to hear announcements made by contractor and driver
f) Do not use public transport for short distance trips
g) No enough space between seats
h) No enough seats for disabled people
i) Bus not waiting for a differently abled person
j) No proper bus stops
k) No exact place to stop the bus

2) When travelling by train
a) No enough hand rails
b) Difficult to get in and get down
c) Steps height is too high
d) No specific place to sit for disabled people
e) Very noisy
f) Not having sufficient time to cross

3) When travelling by three wheelers
a) Entrance is very small
b) No enough space
c) Seat should not be slippery \& should be stable
d) No enough rooms to carry a wheel chair

4) When travelling by van
a) Difficult to get in and get down
b) No steps or Steps height is too high
c) No enough space to carry a wheel chair

5) Issues at terminals
a) Uneven flow, slope, mud
b) No transport facilities on time
c) Not in a proper way
d) No exact places for terminals
e) Difficult to stay in line to get in the bus
f) Entrance to the bus terminal is narrow

The priority level of the road elements were ranked based on the survey results. It was found that sidewalk is the most important road infrastructure and the pedestrian crossing, bus stop, parking and travel information obtained the $2^{\text {nd }}, 3^{\text {rd }} 4^{\text {th }}$ and $5^{\text {th }}$ ranking in the survey. Table - 2 shows the priority level of the road infrastructure elements. This clearly indicates that the sidewalk and the pedestrian crossing should be designed with adequate safety for the differently abled people.

The differently abled people's preference of elements of the public transport modes was analyzed. Table -3 shows the priority level of the elements. It was found that entrance, internal layout, information during travelling 
and terminal were ranked $1^{\text {st }}, 2^{\text {nd }}, 3^{\text {rd }}$ and $4^{\text {th }}$ ranking respectively. It can be seen that majority of the people are not accepted the design of the entrance of public transport mode in Sri Lanka. Internal layout and Information during travelling has equal importance according to the spread of samples.

Table 2 - Preference of Road Environment

\begin{tabular}{|l|c|c|c|c|c|}
\hline \multirow{2}{*}{ Location } & \multicolumn{5}{|c|}{ Priority } \\
\cline { 2 - 6 } & $\mathbf{1}$ & $\mathbf{2}$ & $\mathbf{3}$ & $\mathbf{4}$ & $\mathbf{5}$ \\
\hline Pavement & 6 & 3 & 1 & & 1 \\
\hline $\begin{array}{l}\text { Pedestrian } \\
\text { Crossing }\end{array}$ & 4 & 5 & 1 & 1 & \\
\hline Bus Stops & 1 & 1 & 5 & 1 & \\
\hline Vehicle Parks & & 1 & 2 & 4 & 1 \\
\hline $\begin{array}{l}\text { Travel } \\
\text { information }\end{array}$ & 1 & & & 1 & 5 \\
\hline
\end{tabular}

Table 3 - Preference of Element of Transport Modes

\begin{tabular}{|l|c|c|c|c|}
\hline \multirow{2}{*}{\multicolumn{1}{|c|}{ Location }} & \multicolumn{4}{c|}{ Priority } \\
\cline { 2 - 5 } & $\mathbf{1}$ & $\mathbf{2}$ & $\mathbf{3}$ & $\mathbf{4}$ \\
\hline Entrance & 7 & 2 & 1 & 1 \\
\hline Internal layout & 1 & 3 & 3 & \\
\hline $\begin{array}{l}\text { Information during } \\
\text { travelling }\end{array}$ & 2 & 2 & 4 & 2 \\
\hline Terminals & 1 & 1 & 1 & 5 \\
\hline
\end{tabular}

\subsection{Survey on Existing Transport Modes}

The survey on existing transport modes was conducted to collect dimensions and status of elements which were identified as problematic features for differently abled people in the questioner survey. The results from this survey were used in developing specification. Also these results can be used for future modification on vehicles to suit for differently abled people.

\subsubsection{Shortcoming in Buses}

Currently in Sri Lanka, the buses from Lanka Ashok Leyland and Tata Companies are widely used in all parts of Sri Lanka. Also very few numbers of buses from Isuzu Company are also used in the public transport. Mini buses from Mitsubishi Company (Rosa bus) and Toyota are also widely used in public transport. Table - 4 shows the dimensions of selected design elements. Floor height has been measured from ground to first step of a bus.

Table 4 - Dimension of Some Element of Buses

\begin{tabular}{|c|c|c|c|c|}
\hline \multirow{2}{*}{$\begin{array}{c}\text { Brand } \\
\text { name of } \\
\text { bus }\end{array}$} & \multicolumn{4}{|c|}{ Dimensions $(\mathrm{m})$} \\
\cline { 2 - 5 } & height & $\begin{array}{c}\text { Door } \\
\text { width }\end{array}$ & $\begin{array}{c}\text { Rise } \\
\text { of } \\
\text { steps }\end{array}$ & $\begin{array}{c}\text { Spacing } \\
\text { between } \\
\text { seats }\end{array}$ \\
\hline $\begin{array}{c}\text { Ashok } \\
\text { Leyland }\end{array}$ & 0.80 & 0.70 & 0.25 & 0.20 \\
\hline Tata & 0.85 & 0.65 & 0.25 & 0.25 \\
\hline Isuzu & 0.75 & $\begin{array}{c}0.83 \\
\& 1.40\end{array}$ & 0.25 & 0.40 \\
\hline
\end{tabular}

The problems which may arise with various elements of bus are discussed below by comparing those with requirements for differently abled transport facilities.

\section{(i) Entrance}

The followings are the problems which are identified with the entrance except those for Isuzu buses.

* Width of the entrance is not adequate.

* Steps and handrails are not colour contrast.

* Height of the first step from the ground level is considerably high.

Figure - 3 shows the identified deficiencies of buses' entrance.

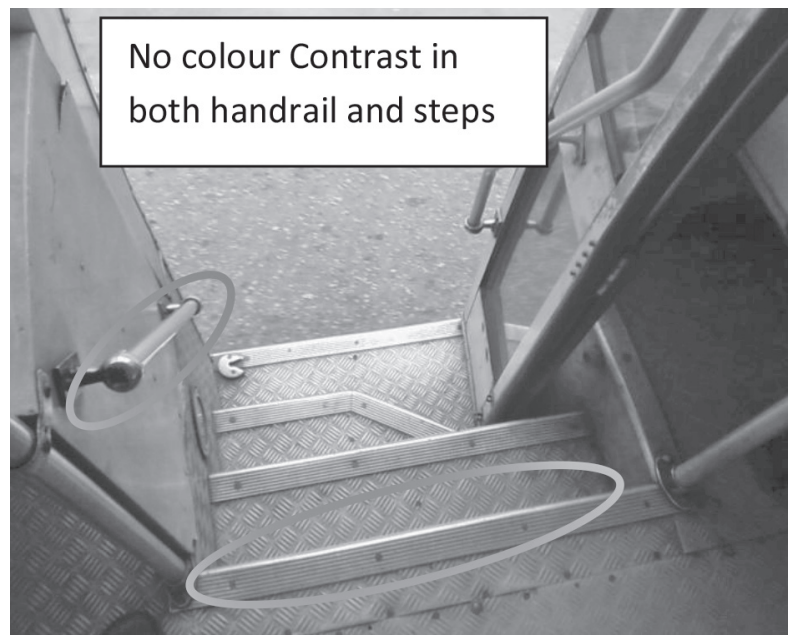

Figure 3 - Identified Problems at Entrance of Bus 


\section{(ii) Boarding of Wheelchair Users}

Table -2 shows that both large and mini buses have high floor height. So it is very difficult to getting into the bus for a person with walking impairment. Also they do not have any boarding devices such as ramp or lift.

\section{(iii) Seats and Wheelchair Space}

Table - 2 shows that the available spaces between seats are not enough for a person with walking impairment to sit comfortably. Also two seats are normally reserved for differently abled people and there is no reserved place for the wheelchair users.

\section{(iv) Handrails}

In most of the buses available handrails are not in a reachable height for a differently abled people to safely getting into the bus. Also they are fixed against the roof without any colour contrast. This makes difficulties especially for the partially blind people to hold the handrails. The Figure -4 shows the identified problem faced with handrails inside the buses.

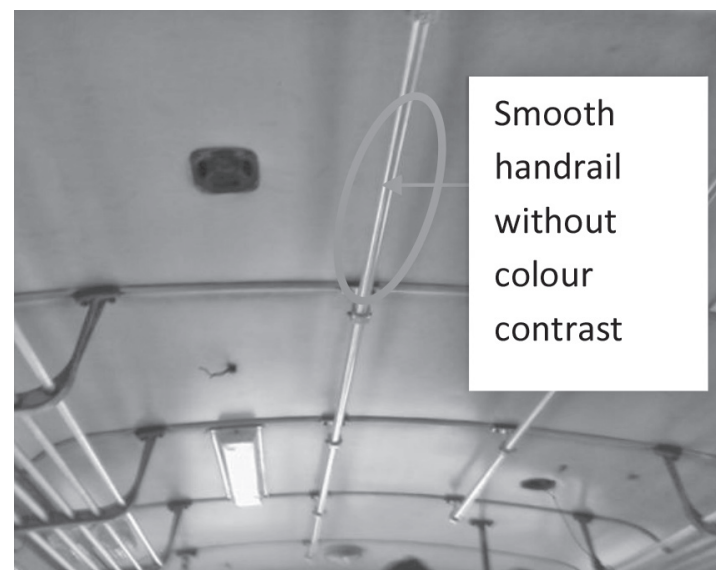

Figure 4 - Handrails Inside the Bus

\section{(v) Bell Pushes}

In most of the buses, the bell inside a bus is operated by either electrically or mechanically. According to the Figure - 5, the buses have bell pushes or pulling cord in the roof level. So it cannot be easily accessed by a person with walking impairment.

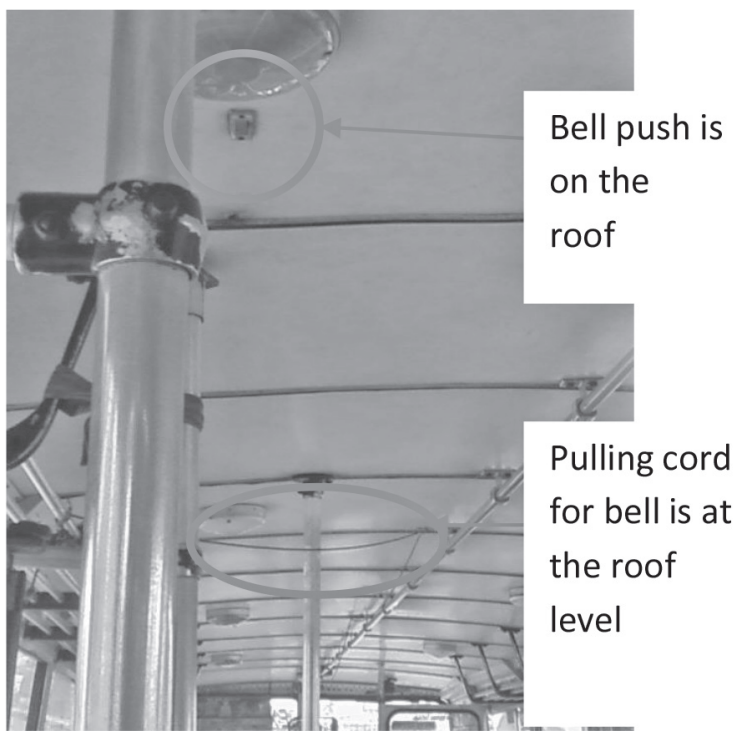

Figure 5 - Bell Push and Pulling Chord

(vi) Signage

* Priority seats for the differently abled people are not signed clearly.

* Origin and destination of routes are not clearly displayed.

* It will be very difficult to read especially during night time.

Figure -6 shows the sign boards displayed of a Bus.

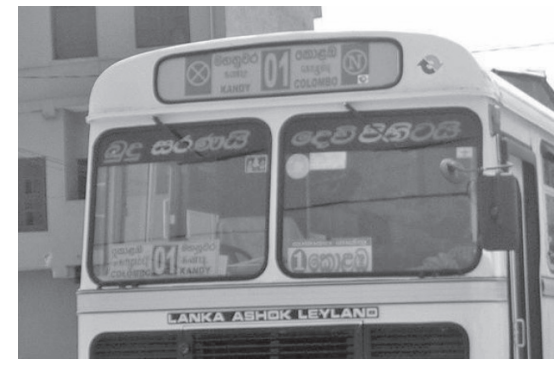

Figure 6 - Sign Board Displayed on Outside of the Bus

\subsubsection{Shortcoming in Trains}

\section{(i) Entrance}

According to Figure -7 , the followings are the major problem with the entrance of the trains.

* Platform and floor of the train's compartments are at different levels.

* Gap between platform and train's compartments.

* No boarding devices for wheelchair users are available. 


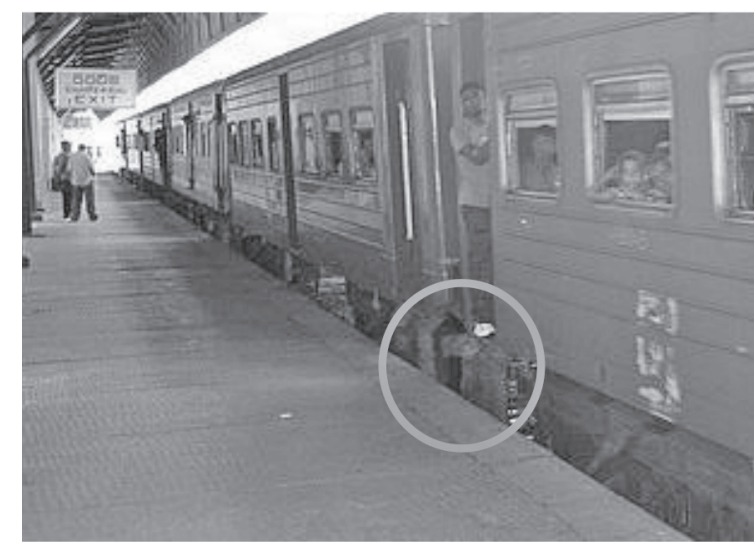

Figure 7 - High Level Difference Between Platform and Compartment Steps of a Train

(ii) Inside the Train

* Handrails are fixed at the roof level.

* No dedicated space for wheelchair users.

\subsubsection{Shortcoming in Taxi (Three Wheelers)}

According to Figure - 8, the major problems which are faced with the three wheeler users are,

* Width of entrance is not adequate

- Clear height from floor to roof is not adequate

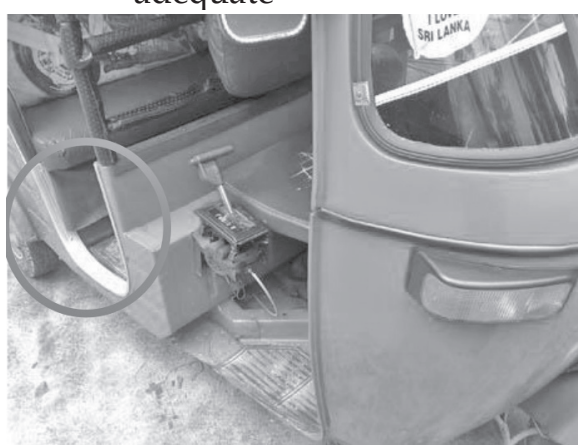

Figure 8 - Outside of a Three Wheeler

\section{Specification to Make Public Transport as Differently Abled Friendly}

Based on results from questionnaire survey analysis and survey on existing transport modes, the following recommendation has been proposed. The standard specified in TRL ORN 21[9] and BS8300[1] are much suitable to Sri Lankan situation. Only the specifications which are suitable to the Sri Lankan situation are selected from those manuals and made it as a single manual.
Figures 9, 10, 11 and 12 extracted from TRL ORN 21 shows the desirable dimensions for elements of public transport modes for usability of them for differently abled people.

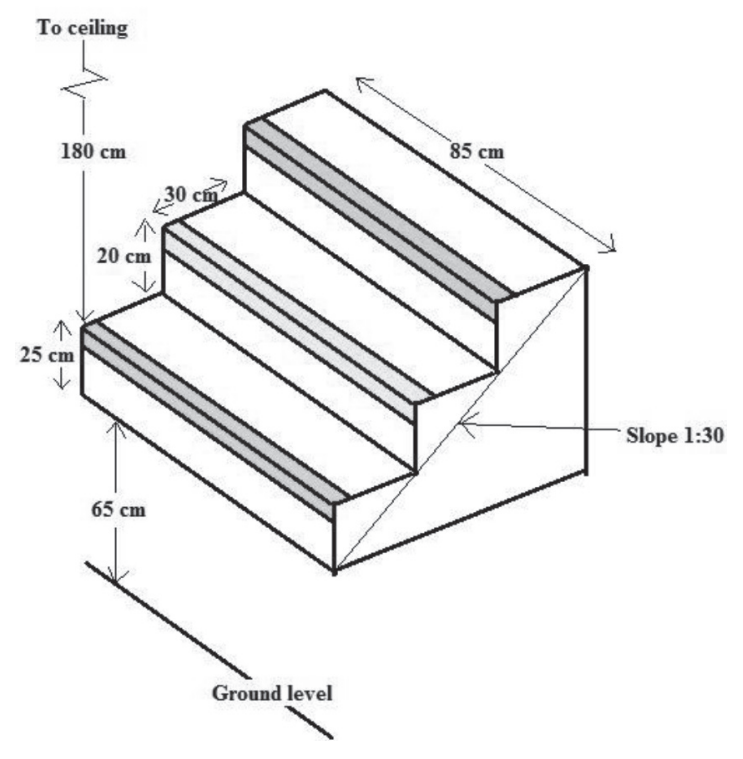

Figure 9 - Specification for Bus Step

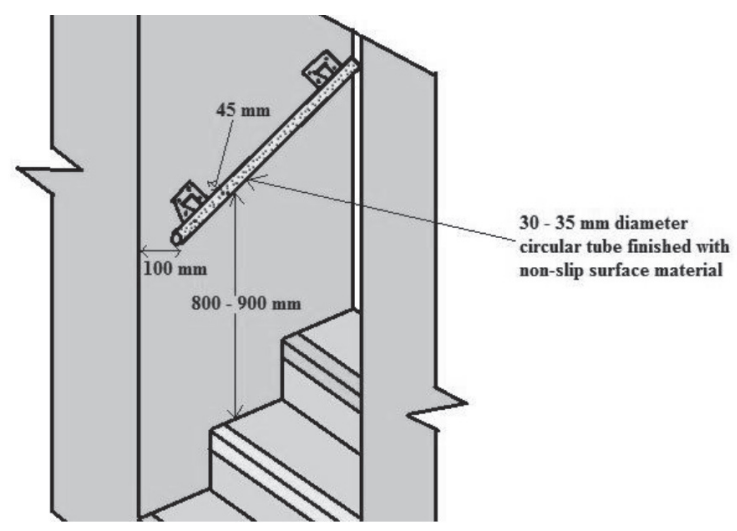

Figure 10 - Specification for Bus Entrance



Figure 11 - Specifications for Seats Inside the Vehicle 




Figure 12 - Specification for Wheelchair Space Inside the Vehicle

There are very few numbers of vehicles (Buses from Isuzu which were donated by Japan after the 2004 Tsunami and new VOLVO buses) have the standard specified in this study for some elements of buses. However, wheelchair lift for differently abled people is not available with them.

\section{Conclusion}

Based on the study, a questionnaire survey was carried out in order to gain information such as the difficulties they face when they are using existing public transportation modes, what types of improvements that they think essential, in what situations should the priority be given when these improvements are done etc. Even if there are many sets of guidelines related to this subject area, they cannot be directly adapted to Sri Lankan conditions.

The questionnaire survey which was done by mail shows the response rate of about $50 \%$. This concludes that people are not willing to participate for mail surveys unless some incentives are given for the participants who successfully completed the questioner.

Most of the time, differently abled people in Sri Lanka are staying with family and depend on family for their survival. So they do not know the difficulties which will be faced by them during travelling. The differently abled people who are working most of the time use their own vehicle for travelling. Only limited people use public transport. It was found that most of them are not happy about the existing design of entrance of the public transport modes. It was found that dimensions of the entrance of all the available transport modes have not satisfied the specified dimensions in standard.

Existing specifications for the public transport modes regulated by the National Transport Commission do not have specified needs for differently abled people. Survey results of the existing transport modes showed that most of the vehicles that are used for public transport do not have adequate facilities for the differently abled people. But there are very few numbers of vehicles (Buses from Isuzu which were donated by Japan after the 2004 Tsunami and new VOLVO buses) have the standard specified in this study for some elements of the buses. However, wheelchair lift is not available with them.

The new sets of guidelines are developed based on the guidelines which are used by other countries considering the suitability for Sri Lankan conditions. So, it is essential to use these guidelines by the registrar of motor vehicles and the National Transport Council in registering and regulating the public transport modes. It will create a barrier free environment for differently abled people in Sri Lanka.

\section{References}

1. BS8300: 2009 - Design of buildings and their approaches to meet the needs of disabled people, BSI Standard \& Publications, London, UK.

2. Sri Lanka, The Gazette of Democratic Socialist Republic of Sri Lanka (2006), Disabled Persons' (Accessibility) Regulation No 1,467/15 - 17/10/2006, Colombo.

3. ADB, 2005, Disabled People and Development Sri Lanka Country Report, 2005, Asian Development Bank, viewed 06 October, 2010.

http://www.adb.org/Documents/Report s/Disabled-People-Development/SriLanka.pdf

4. DPTAC, 2000, Re-statement of Recommended Specification for Buses Used to Operate Local Services, Disabled Persons Transport Advisory Committee (DPTAC), viewed 8 November 2010, 
http://dptac.independent.gov.uk/pubs/i ndex.htm\#01

5. Khechen, M., 2003, Accessibility for the Disabled - A Design Manual for a Barrier Free Environment, ESCWA, viewed 10 October 2011

http://www.epdp.eu/ebooks/united/bui 1t/02.pdf

6. Kieran Broome, Linda Worrall, Kryss McKenna and Duncan Boldy, 2010, Priorities for an Age-Friendly Bus System, viewed 28 July 2011,

http:// muse.jhu.edu/login?uri=/journals Lcanadian_journal_on_aging/v029/29.3.br oome.pdf

7. Oxley, P., 2002, Inclusive mobility - a guide to best practice on access to pedestrian and transport infrastructure, viewed on 10 January 2011, www.dft.gov.uk.

8. Sri Lanka, 2001, Department of census and statistics-, Census and statistics data, 2001, viewed 6 October 2010, http://www.statistics.gov.lk/PopHouSat LDes_Chra.asp.

9. Veter, C., J., Sentinella, J., Rickert, T., Maunder, D., Venkatesh, A., 2004, TRL Overseas Road Note 21 - Enhancing the mobility of disabled people: Guidelines for practitioners, Department of International Development (DFID), viewed 6 November 2010,

http://www.transport-

links.org/transport_links/filearea/publica tions/1_831_ORN\%2021.pdf> 
